\title{
DEVELOPMENT OF V-SHAPED COMPRESSION SOCKS ON CONVENTIONAL SOCKS KNITTING MACHINE
}

\author{
Hafiz Faisal Siddique ${ }^{1}$, Adnan Ahmed Mazari ${ }^{1}$, Antonin Havelka ${ }^{1}$, Tariq Mansoor $^{1}$, Azam Ali $^{2}$, Musaddaq Azeem $^{1}$ \\ ${ }^{1}$ Technical University of Liberec, Clothing Technology, Liberec \\ ${ }^{2}$ Technical University of Liberec, Material Engineering, Liberec
}

\begin{abstract}
:
The aim of this study was to develop V-shape compression socks that should exert graduated lateral compression around the leg. For the development of socks, three types of yarns: main yarn (MY), plaiting yarn (PY) and inlaid yarn (IY) were used. Each yarn contained spandex yarn as the core. Machine adjustments were optimized to achieve the special V-shaped compression socks according to size of the wooden leg. Eighteen socks samples were developed and quantified for pressure exertion at ankle and calf portions using the MST MKIV, Salzmann pressure measuring device. Consequently, only two socks samples were accepted, which had the pressure exertion values of $21 \mathrm{mmHg}$ and $23 \mathrm{mmHg}$ with graduation percentage of $73 \%$ and $80 \%$, respectively.
\end{abstract}

\section{Keywords:}

Core Spun yarn, conventional socks machine, in-laid yarn, lateral compression ( $\mathrm{mmHg})$, main yarn, plating yarn, $v$-shaped socks.

\section{Introduction}

Compression socks are a highly acclaimed textile garment for pressure exertion on the lower part of the leg. It is used to reduce venous hyper pressure [1].

Mechanism of the action is the lowering of pressure exertion from ankle to calf portion of the leg. The pressure exertion value should be highest at the ankle and must gradually decrease along the direction of the leg. This varying degree of compression pressure propagates and regulates blood flow, keeps the muscles in-line at the right position to mitigate the injury risk, gives relief to many chronic venous disease patients and is used for therapeutic purposes [2,3]. In textile literature, it is studied that an inappropriate value of lateral compression may affect the energy, work competence and the wearer's health. But insufficient pressure may also limit the efficiency and reduce the aesthetic appeal of the garment. Higher extent of pressure may reduce heart and lung functions that may cause serious damage to health $[4,5]$.

The intensity of compression pressure used for various diseases is categorized as moderate up to $(20-30 \mathrm{mmHg})$ and firm compression $(30-40 \mathrm{mmHg}$ ). This extent of pressure is recommended to treat the circulatory and vascular medical conditions as well for tired, sore, swollen, or aching legs.

Theoretically, the extent of pressure exerted on the leg depends on the radius $(R)$ of the leg and reversal force $T(N)$.

According to Laplace's Law (5),

$$
\mathrm{P}(\mathrm{Pa})=\frac{\mathrm{T}(\mathrm{N})}{\mathrm{R}(\mathrm{cm})}
$$

Where $\mathrm{P}=$ Pressure, $\mathrm{T}=$ Reversal fabric tension, $\mathrm{R}=$ Radius of leg

For the pressure measurement on patient's leg, the circumference of ankle and calf portion is required (1), so equation (1) can be modified to

$$
\mathrm{P}(\mathrm{Pa})=\frac{\mathrm{T}(\mathrm{N}) \times 2 \pi}{\mathrm{C}(\mathrm{cm})}
$$

Where $\mathrm{P}=$ Pressure, $\mathrm{T}=$ Reversal fabric tension, $\mathrm{C}=$ Circumference of leg or

$$
(\mathrm{Pa})=\frac{\mathrm{T}(\mathrm{N}) \times 2}{\mathrm{~W}(\mathrm{~cm})}
$$

Where $\mathrm{P}=$ Pressure, $\mathrm{T}=$ Reversal fabric tension, $\mathrm{W}=$ width of socks [6-9].

Using Laplace's formula, it is evident that the operative pressure should be greatest at the point of minimum girth area/radius and have the slightest pressure at the point of maximum girth area/ radius. Apart from the position of the leg, the circumference (Thin or thick) of the leg also needs optimum or lower pressure on cutaneous and subcutaneous skin layers, which satisfies the Laplace's Law (3).

MST MKIV (Salzmann AG, St Gallen, Switzerland) pressure measuring device is used for this research. It is comprised 
of thin plastic sleeve ( $4 \mathrm{~cm}$ wide, $0.5 \mathrm{~mm}$ thick), with four paired electrical contact points connected to an air pump and a pressure transducer. Sensors are located to the medial (inner) side of the wooden leg placed between the leg and socks. The air pump inflates the envelope until the contacts open (when the inner pressure exerted by the air is just above the external pressure due to the compression device). When the contacts open, the transducer reads the pressure at the located measuring points and is displayed digitally with $1 \mathrm{mmHg}$ resolution. Two lengths of the probe are available. Only the shorter one (34 cm long) with four contact points was used in this study $[1,8]$.

Normally, socks (weft knitted) made up of two different types of yarns, that is, looping yarn and inlaid yarn. Loop forming yarns exhibit texture and provide a different feel. Inlaid yarn provides stretch, optimum pressure, intimate contact and grip over the leg portion. The loop-forming yarns like body yarn (spun/filament) and plated yarn (air covered) form the loops together. Inlaid yarn (double covered yarn) is integrated into each loop of every course [3,8-10]. Various studies exist in which different fiber/yarn types (varying spandex yarn linear densities and compositions) [2,9-11], different types of spun/ core spun yarns of different linear densities [7], different kind of inlaid yarn,[2] varying tension by increasing or decreasing the ultra-feeder yarn tensions into the knitting machine and different fabric structures (manufactured and readymade), ${ }^{[7]}$ different sizes and shapes of the substrate (cylindrical tube or wooden leg) were used to exert maximum pressure at ankle and optimum graduation [4]. But there is no study in which the shape of the socks is changed by figuring out the machine adjustments and using different linear densities of spandex yarn on the conventional socks manufacturing machine.

Main objective of this research is to identify the optimum machine settings to achieve the desired V-shape and to meet the pressure recommended for CCLI and CCL II socks exhibiting optimum graduation $\%$ between 70 to $80 \%$.

In this study, we conducted various trials to achieve the desired V-shape with compatible dimensions of the wooden leg. Required shape was achieved by introducing different zones by altering the graduation motor speed and the degree of needles (height) at only the leg portion of the socks.

V-shaped structure of the socks was designed to achieve the narrowest circumference at ankle and the widest at calf portion of the wooden leg, as necessary to simulate the actual compressions socks. During the development of V-shape of the socks, graduation within the socks was considered carefully as graduation was taken in consideration in the previous development related researches.

\section{Experimental}

\subsection{Materials (Yarns)}

Compression socks comprised of three yarns types, that is, main, plated and inlaid, abbreviated as main yarn (MY), plaited yarn (PY) and inlaid yarn (IY).

\subsubsection{Main/Body yarn}

Three types of main yarns (core Spun) were selected (abbreviated as MY1, MY2 \& MY3), as shown Fig. 1. All had the same overall linear density, that is, 29.52 tex but spandex yarn of different linear densities, that is, 4.4 tex, 7.8 tex and 11.8 tex, respectively. Here, MY1: 4.4 tex Spandex $-29.52 / 1$ tex core spun cotton 96\%, MY2: 7.8 tex Spandex - 29.52/1 tex core spun cotton $93 \%$ and MY3: 11.8 tex Spandex - 29.52/1tex core spun cotton $90 \%$. Testing results of the main yarn are given below in Table 1.

Table 1. Main yarn results

\begin{tabular}{|c|c|c|c|c|c|}
\hline \multirow{2}{*}{$\begin{array}{l}\text { Sr. } \\
\text { No }\end{array}$} & \multirow{2}{*}{ Main Yarn Codes } & \multicolumn{2}{|c|}{ Yarn Linear Density (tex) } & \multirow{2}{*}{ Draw ratio } & \multirow{2}{*}{$\begin{array}{c}\text { Elastane } \\
\text { Composition (\%) }\end{array}$} \\
\hline & & Resultant & Elastane & & \\
\hline 1 & ${ }^{*}$ MYELD1 & 29.52 & 4.4 & 3.48 & 4.32 \\
\hline 2 & *MYELD2 & 29.52 & 7.8 & 3.64 & 7.22 \\
\hline 3 & ${ }^{*}$ MYELD3 & 29.52 & 11.7 & 3.65 & 10.83 \\
\hline
\end{tabular}

${ }^{\star}$ MY: Main Yarn, E: Elastane, LD: Linear density

Table 2. Properties of the inlaid yarns

\begin{tabular}{|c|c|c|c|c|c|c|}
\hline \multirow{2}{*}{$\begin{array}{c}\text { Sr. } \\
\text { No }\end{array}$} & \multirow{2}{*}{$\begin{array}{c}\text { Inlaid Yarn } \\
\text { Codes }\end{array}$} & \multicolumn{2}{|c|}{ Yarn Linear Density (tex) } & \multirow{2}{*}{$\begin{array}{c}\text { Draw ratio } \\
\%\end{array}$} & $\begin{array}{c}\text { Elastane } \\
\text { Composition } \\
\text { (\%) }\end{array}$ \\
\cline { 3 - 7 } & DCV Resultant & Nylon & Elastane & 1.63 & 17.27 \\
\hline 1 & *IYELD1 & 20.22 & 15.55 & 13.3 & 1.85 & 18.6 \\
\hline 2 & *IYELD2 & 21.11 & 15.55 & 15.5 & 1.56 & 34.08 \\
\hline 3 & *IYELD3 & 27.33 & 15.55 & 33 & & \\
\hline
\end{tabular}

*IY: Inlaid Main, E: Elastane, LD: Linear density 


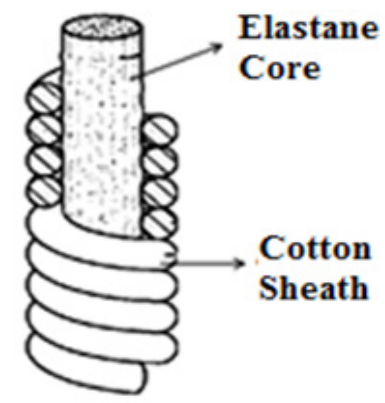

Figure 1. Core Spun yarn [3]

\subsubsection{Inlaid Yarn}

Three types of double covered nylon filament yarns were selected, as shown in Fig. 2. These can be abbreviated as IY1, IY2 and IY3. Each type contained spandex yarn of different linear densities, that is, 13.3 tex, 15.5 tex and 33 tex but a fixed resultant linear density of 15.55 tex/24f/1. Here, IY1: 13.3 tex - 15.55/24f/1tex Raw White Nylon DCV 17\%, IY2: 15.50 tex - 15.55/24f/1tex Raw White Nylon DCV 19\% and IY3: 33.0 tex - 15.55/24f/1tex Raw White Nylon DCV 34\% (DCV: double covered). Testing results of inlaid yarns are given in Table 3.

\subsubsection{Plaiting yarn}

Two types of nylon air covered yarns were selected abbreviated as PY1 and PY2, as shown in (Fig 3), having different draft values (2\% and $3.2 \%)$ were selected. Here PY1: 2.2 tex
Spandex - 7.77 tex/24filamnet/1 Raw White Nylon ACV 8\%, PY2: 2.2 tex Spandex - 7.77 tex/24filament/1 Raw White Nylon ACV $12.5 \%$ [ACV: air covered]. Testing results of plating yarn are given in Table 2.

\section{Methods}

\subsection{Machine specifications and adjustments}

Single cylinder circular knitting machine Lonati (type L-462, model 2005) having 12 gauge, 3.75" diameter, 250 rpm speed, 2 feeders and 168 numbers of needles was used to develop the compression socks.

To achieve the desired shape at leg portion, regular machine settings were changed to special settings. For this, two types of adjustments: (I) speed of graduation motor and (II) changing the degree of needles was made. Total 322 courses were inserted in the leg portion (RIB $1 \times 1$ ) of each socks sample. RIB structure was designed on the leg portion instead of plain, as it grips the legs with more severity than the plain structure. The reason for a higher grip at leg portion is due to the presence of inlaid yarns that keeps moving inside the loops of the courses. The lateral compression of socks majorly relates with the linear density of spandex yarn. The results given in Table 5 present that the socks samples in which the inlaid yarn of highest linear density is used exhibit more pressure than the socks samples in which the inlaid yarn of lower densities is used. Similarly, the

Table 3. Plated yarn results

\begin{tabular}{|c|c|c|c|c|c|c|}
\hline \multirow{2}{*}{$\begin{array}{c}\text { Sr. } \\
\text { No. }\end{array}$} & \multirow{2}{*}{ Plating Yarn Code } & \multicolumn{3}{|c|}{ Yarn Linear Density (tex) } & \multicolumn{2}{c|}{ Elastane } \\
\cline { 3 - 6 } & ACV & Sheath & Elastane & Draw ratio (\%) & Composition \% \\
\hline 1 & *PYED1 & 9.11 & 7.77 & 2.2 & 3.2 & 8 \\
\hline 2 & *PYED2 & 9.44 & 7.77 & 2.2 & 2 & 12.5 \\
\hline
\end{tabular}

*PY: Plated Yarn, E: Elastane, D: Draft

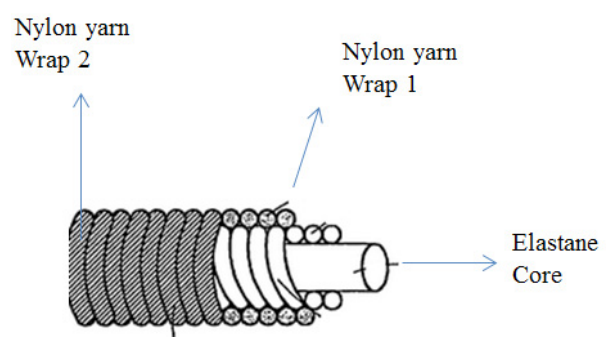

Figure 2. Double covered Nylon yarn [13]

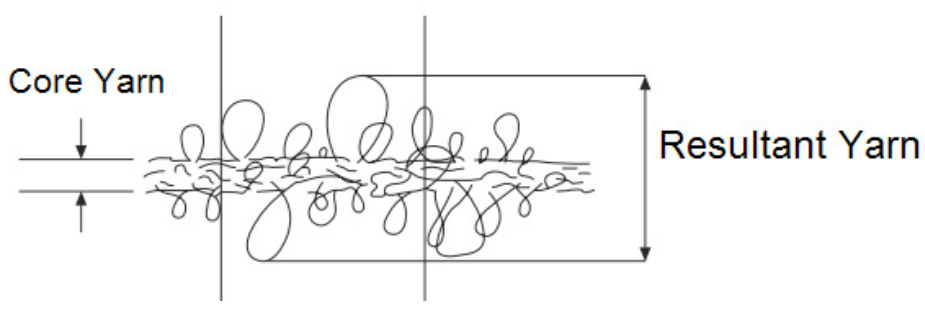

Figure 3. Side view of ACV yarn (a) resultant and elastane yarn [12] 
same trend was observed in case of main yarns; as the linear densities of spandex in core spun yarn increases, it exhibits more lateral compression but we have to consider the medical factor that involves appropriate graduation (\%).

Desired shape with maximum compression pressure at ankle is achieved by creating seven zones with respect to the graduation motor and three with respect to the degree of needles. In seven zones, each zone contains 46 courses with constant speed reduction of $200 \mathrm{rpm}$ of graduation motor. The speed of graduation motor at calf was $1400 \mathrm{rpm}$, which was reduced to $600 \mathrm{rpm}$ at ankle.

Further, the three zones were introduced by decreasing the degree of needles from calf portion (400 degree) to ankle (100 degree) portion. Each zone contains 108 courses with the lowest degree of needles (lowest height and stitch length) at ankle and highest at calf portion.

\subsection{Preparation of V shaped socks}

All the three yarns (main, plating and Inlaid) were loaded on socks knitting machine. Two different yarns, looping yarn and inlaid yarns, were fed to machine. The main yarn was fed along with the plating yarn to form loops. All the yarns were changed simultaneously as the design of the experiment and eighteen socks samples were prepared. The desired V- shaped socks is shown in Figure 4.

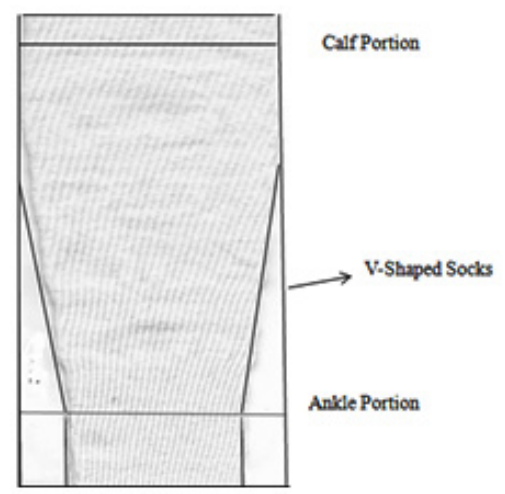

Figure 4. Facial view of V-shaped compression socks

All the samples were tested for compression pressure at ankle and calf portion using the MST MKIV pressure measuring device and wooden leg (figure 5). The wooden leg selected had the specifications as given in Table 2.4.

\subsection{Specification of v-shaped compression socks}

The developed $\mathrm{V}$-shaped socks had ankle widths ranging from $6.5 \mathrm{~cm}$ to $8.5 \mathrm{~cm}$ and calf widths ranging from $9 \mathrm{~cm}$ to 10.5 . This difference in widths is due to machine adjustments and varying linear densities of the spandex yarns. Fernando et al. studied that by increasing the tension of the spandex yarn and loop length (degree of needles) of rigid material, there is an increase in weight per unit area and thickness, which ultimately affects the width of socks at ankle and calf according to machine adjustments [9].

In this study, we were unable to measure wales per inch, courses per inch and density of fabric because of varying density at ankle due to least degree of needles, lowest graduation motor speed, stitch density variation and width variation from ankle to calf portion. The desired V-shape is shown in Figure 4 and the wooden leg used for testing in Figure 5.

Table 4. Width of V-shaped socks and wooden leg at ankle /calf portions

\begin{tabular}{|c|c|c|c|}
\hline $\begin{array}{c}\text { Sr. } \\
\text { No }\end{array}$ & Socks width & Unit (cm) & $\begin{array}{c}\text { Wooden leg } \\
\text { Width } \mathbf{( c m )}\end{array}$ \\
\hline 1 & Ankle & $6.5-8.5$ & 8.28 \\
\hline 2 & Calf & $9-10.5$ & 12.42 \\
\hline
\end{tabular}

\subsection{Measuring the interfacial pressure, Graduation $\%$ and} Reduction $\%$

The compression pressure at ankle/calf portion along with the graduation \% (G \%) was measured using the MST MKIV device as, shown in Figure 5.

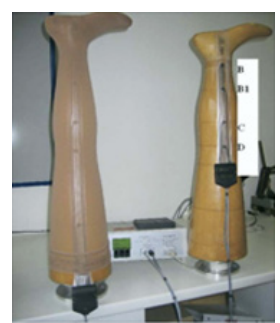

Figure 5. MST Salzmann instrument and wooden leg

All the developed socks samples were donned to the wooden leg with an attachment of pressure measuring sensors. Compression pressure values at ankle portion, calf portion and graduation percentage ( $G \%$ ) was calculated. $G \%$ is a very important factor keep in mind that it is helpful in regulating the blood flow. Liu et al. (2005) studied that the compression socks should exert maximum pressure at ankle decreasing upwards (hip side) This gradient change in pressure generates the pressure between capillaries and enhances the rate of blood flow through the veins [7].

Graduation percentage ( $G \%$ ) from ankle to calf portion is calculated using the formula:

Graduation percentage $(\mathrm{G} \%)=(\mathrm{Pc} \div \mathrm{Pa}) \times 100$

$\mathrm{P}^{\mathrm{c}}=$ Pressure at calf portion, $\mathrm{Pa}=$ Pressure at ankle portion (10)

The lateral compression and graduation \% (G \%) depends on socks width and reduction $\%$, as per equation (3).

Reduction percentage $\%$ is actually the difference in the dimension of wooden leg and compression socks at a specific point. It can be calculated using the formula ${ }^{[9,14-16]}$ given below:

Width Reduction \% $=(($ Leg width - Socks Width $) \div$ Leg width $)$ $\times 100$ 
Table 5. Design of experiment with testing results

\begin{tabular}{|c|c|c|c|c|c|c|c|c|c|}
\hline $\begin{array}{l}\text { Sr. } \\
\text { No }\end{array}$ & $\begin{array}{l}\text { Fabric } \\
\text { code }\end{array}$ & $\begin{array}{l}\text { MYELD } \\
\text { (tex) }\end{array}$ & $\begin{array}{l}\text { IYELD } \\
\text { (tex) }\end{array}$ & $\begin{array}{l}\text { PYED } \\
\text { (ratio) }\end{array}$ & $\begin{array}{c}\text { Width at } \\
\text { ankle }(\mathrm{cm})\end{array}$ & $\begin{array}{l}\text { Width at } \\
\text { calf }(\mathrm{cm})\end{array}$ & $\begin{array}{c}\text { Ankle } \\
\text { Pressure, } \\
\text { Pa(mmHg) }\end{array}$ & $\begin{array}{c}\text { Calf } \\
\text { Pressure, } \\
\text { Pc (mmHg) }\end{array}$ & $\begin{array}{c}\text { Graduation } \\
\text { Percentage } \\
\text { GP (\%) }\end{array}$ \\
\hline 1 & M1I1P1 & 4.4 & 13.3 & 2 & 7.8 & 9.3 & 13 & 11 & 84.61 \\
\hline 2 & M1I1P2 & 4.4 & 13.3 & 3.2 & 7.6 & 10 & 15 & 14 & 93.3 \\
\hline 3 & $\mathrm{M} 1 \mathrm{I} 2 \mathrm{P} 1$ & 4.4 & 15.5 & 2 & 7.5 & 10 & 13 & 11 & 84.6 \\
\hline 4 & $\mathrm{M} 1 \mathrm{I} 2 \mathrm{P} 2$ & 4.4 & 15.5 & 3.2 & 7.7 & 9.4 & 13 & 14 & 107.69 \\
\hline 5 & M1I3P1 & 4.4 & 33.0 & 2 & 7.6 & 9.6 & 20 & 15.99 & 79.95 \\
\hline 6 & M1I3P2 & 4.4 & 33.0 & 3.2 & 7.2 & 10 & 23 & 17 & 73.91 \\
\hline 7 & M2I1P1 & 7.8 & 13.3 & 2 & 6.5 & 9 & 16 & 14 & 87.5 \\
\hline 8 & M2I1P2 & 7.8 & 13.3 & 3.2 & 8.3 & 10.5 & 18 & 16 & 88.8 \\
\hline 9 & M2I2P1 & 7.8 & 15.5 & 2 & 7 & 9.5 & 17 & 15 & 88.23 \\
\hline 10 & $\mathrm{M} 2 \mathrm{I} 2 \mathrm{P} 2$ & 7.8 & 15.5 & 3.2 & 7.7 & 9.4 & 18 & 17 & 94.44 \\
\hline 11 & M2I3P1 & 7.8 & 33.0 & 2 & 7.5 & 9.5 & 26 & 22 & 91.66 \\
\hline 12 & M2I3P2 & 7.8 & 33.0 & 3.2 & 7 & 9.2 & 24 & 22 & 91.66 \\
\hline 13 & M3I1P1 & 11.7 & 13.3 & 2 & 7.6 & 9.6 & 17 & 16 & 94.11 \\
\hline 14 & M3I1P2 & 11.7 & 13.3 & 3.2 & 8 & 9.7 & 16 & 16 & 100 \\
\hline 15 & M3I2P1 & 11.7 & 15.5 & 2 & 8 & 9.2 & 19 & 16 & 84.21 \\
\hline 16 & $\mathrm{M} 3 \mathrm{I} 2 \mathrm{P} 2$ & 11.7 & 15.5 & 3.2 & 8.5 & 10.2 & 17 & 18 & 105.88 \\
\hline 17 & M3I3P1 & 11.7 & 33.0 & 2 & 8 & 10 & 22 & 22 & 100 \\
\hline 18 & M3I3P2 & 11.7 & 33.0 & 3.2 & 7.8 & 10.5 & 23 & 22 & 95.65 \\
\hline
\end{tabular}

All the results of width, reduction percentage (\%), graduation percentage (\%), linear densities (LD) of all spandex yarns.

\section{Results and Discussions}

In this study, we have followed the European standard method (German RAL), which recommends the intensity of pressure necessary for treating compression related diseases. According to the method, socks can be categorized to Light: CCL1 (18 to $21 \mathrm{~mm} \mathrm{Hg}$ ) and medium CCLII $(23 \mathrm{~mm} \mathrm{Hg}$ to $30 \mathrm{~mm} \mathrm{Hg}$ ) classes.

\subsection{Ankle width impact on pressure value and Graduation $\%$}

Figure 6 represents the compression pressure values at ankle. All the socks samples were analyzed and only 5 samples out of eighteen were found to exert pressure above $20 \mathrm{mmHg}$ at the ankle, abbreviated as M1I1P1, M1I2P1, M3I2P1, M1I3P1 and M1I3P2. Rest 13 socks samples were rejected due to pressure exerting values below than $20 \mathrm{mmHg}$, which were lesser than aimed for in the study.

The selected 5 sample socks had the width range $7 \mathrm{~cm}$ to 8 $\mathrm{cm}$ at the ankle portion, while the wooden leg had the width $8.28 \mathrm{~cm}$ as measured from its circumference at the point of minimum girth area (ankle). Width difference between socks and wooden leg gives us reduction percentage (\%) value, which significantly influences the lateral force of exertion. As per equation (3), the reduction percentage value is inversely proportional to the width of wooden leg.

There are many studies that state that as the width of socks decreases as compared to the width of wooden leg, there occurs an increase in the force of exertion on the surface of the leg. Different researchers have used different techniques for increasing this exertion force.

DeVasconcelos et al. (2013) found that by increasing the tension of spandex yarn and decreasing the loop length (degree of needles) of the rigid material, an occurrence of increase in the weight per unit area and thickness takes place, which ultimately affects the width of socks at ankle and calf according to machine adjustments [17]. Chattopadhyay et al. (2012) increased this exertion force by increasing the pre-tension at the feed stage of inlaid yarn, which led to an increase in the contraction of elastic yarns, ultimately pulling the surrounding fabric loops and consequently decreasing the width size and increasing the loop length of fabric [14].

Tsujisaka et Al. studied that when the socks are stretched to a certain extent, there occurs an increase in the compression pressure, as it induces stress relaxation and causes a feel of pressure changes [18]. 


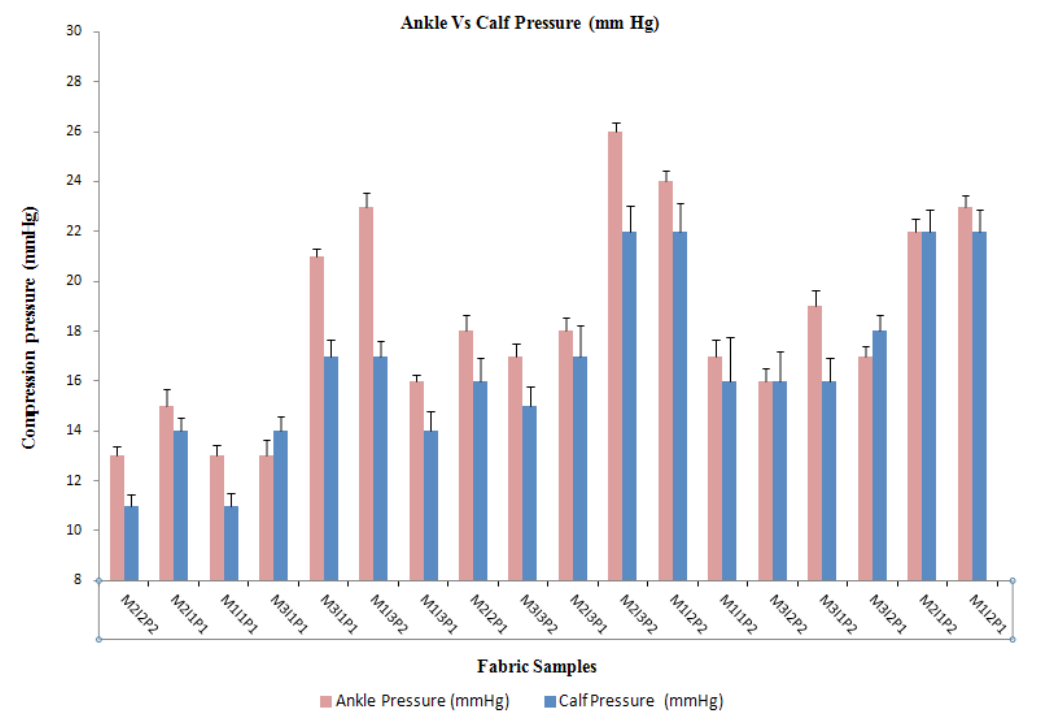

Figure 6. Compression pressure at ankle and calf portion

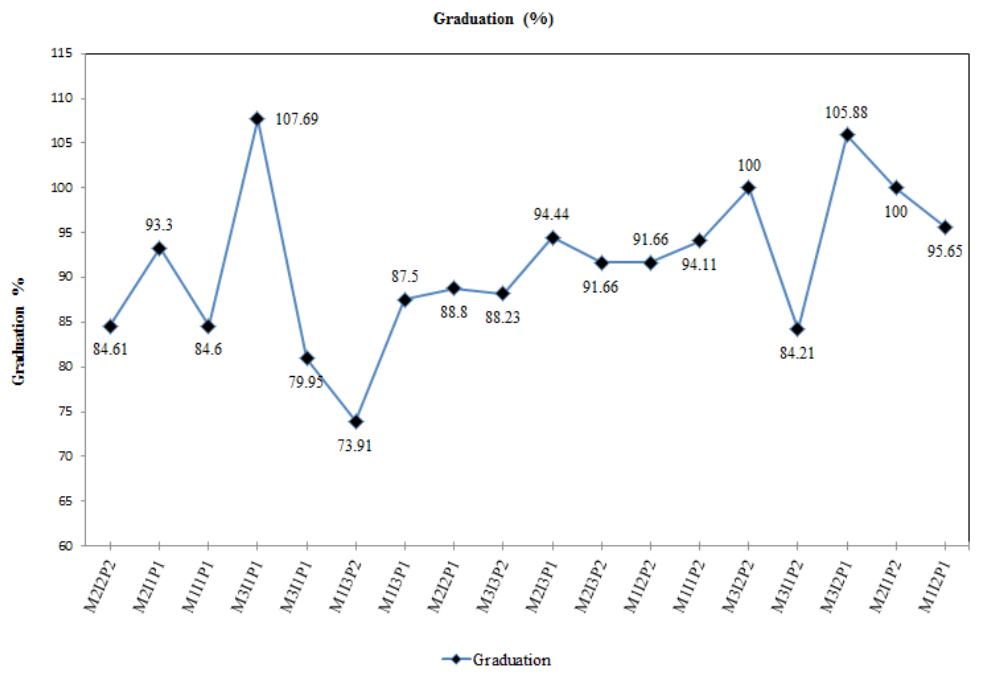

Figure 7. Graduation percentage of socks samples

Accordingly, to Laplace law equation, $P=T / R$, the intensity of pressure exertion by compression socks is directly related to the radius of the body. As radius increases, fabric tension on the surface of the body increases, which ultimately increases the intensity of compression pressure $[14,19]$.

Some researchers also studied the effect of strain \% on compression pressure value and concluded that as the strain $\%$ increases due to decrease in the size of the socks, there occurs an increase in compressive pressure on the surface of skin $[20,21]$.

Figure 7 shown below represents the graduation \% (G \%) values of all the socks samples that are different from each other. This difference is due to a change in the physical specifications of the socks as compared to the fixed size of the wooden leg.

After selecting 5 socks samples that exerted maximum pressure, above $20 \mathrm{mmHg}$, as shown in figure 6, we reanalyzed them for their $\mathrm{G} \%$ from the results given in Figure 7. Out of the 5 socks samples selected, we found that there were only two socks samples that acquires $G \%$ values below $80 \%$, so rest of the three sock samples abbreviated as M1I1P1, M1I2P1 and M1I3P1 were rejected due to poor G $\%$ of more than $80 \%$. As many researchers have worked on the development of compression socks, but only a few have focused on the graduation percentage (\%), they recommended that the compression socks should possess graduation percentage $\%$ between $50 \%$ to $80 \%$ from ankle to calf, for compression class I and Class II and for compression class III and class IV, the graduation $\%$ should range between $50 \%$ to $70 \%[8,16,19]$.

On the basis of this condition, we recommend only 2 socks samples M1I3P1 and M1I3P2 that have achieved compression pressure at ankle up to $21 \mathrm{mmHg}$ and $23 \mathrm{mmHg}$ with minimum graduation percentages (\%) of $79.95 \%$ and $73.91 \%$ simultaneously.

\subsection{Calf width impact on pressure value and Graduation \%}

Figure 6 and Figure 7 present the intensity of compression pressure at calf portion and graduation percentage (G \%).

All the socks samples were observed for their compression pressure at calf and 13 socks samples were rejected for having calf pressure below $10 \mathrm{mmHg}$. 
Only 5 socks samples were accepted that had exerting the pressure above $10 \mathrm{mmHg}$, abbreviated as M1I1P1, M1I2P1, M1I3P1, M1I3P2 and M3I2P1. The accepted socks samples' widths were measured to range from $10 \mathrm{~cm}$ and $9.7 \mathrm{~cm}$. Wooden leg width at calf portion was $12.42 \mathrm{~cm}$ calculated from the circumference of leg. The difference in width of socks sample and wooden leg gives us the reduction percentage (\%) values at calf, as shown in Figure 9. Figure 9 demonstrates the reduction $\%$ values in the accepted socks samples M1I3P1 and M1I3P2, which is close to $23 \%$ and $20 \%$ and causes exertion of lateral compression at calf.

Partsch et al. (2006) mentioned that as the circumference of leg increases to $1 \mathrm{~cm}$, we can elongate the fabric sample by $1 \mathrm{~cm}$, transposing the difference into local pressure exerted at different segments of the leg [8].

According to the Laplace law, $\mathrm{P}(\mathrm{mmHg})=[\mathrm{T} /$ width $] \times 166.66$, the intensity of pressure is inversely proportional to the width of the wooden leg. As the width of the compression socks increases at calf portion compared to ankle width, there occurs a decrease in the areal density, stitch density and tightness of the fabric; this leads to an increase in tensibility and causes lowest resistance to deformation,[22] ultimately decreasing the thickness and tensile strength values.

Harpa et al. (2010) and Dalbey et al. (2011) reported that the pressure at calf portion should be minimum at calf than ankle portion essential to regulate the blood flow and to avoid unnecessary clotting inside the veins [2,3]. For this, there is a necessity of appropriate $\mathrm{G} \%$ values, which only the two socks samples abbreviated as M1I3P1 and M1I3P2 are able to attain, as shown in Figure 9.

As already mentioned about the requirement of $G \%$ values, we found that only 2 socks samples, abbreviated as M1I3P1 and $\mathrm{M} 1 \mathrm{I} \mathrm{P} 2$, were able to achieve the optimum gradation, that is, between $70 \%-80 \%$.

\section{Conclusion}

In this study, we used varying linear densities of yarns (main yarn, plating and inlaid yarn) and newly designed machine adjustments (fixed for all samples preparation) to achieve the desired V-shaped compression socks. The conventional socks knitting machine was used for the development of the targeted compression level and graduation percentage (G \%). Only 2 socks samples out of 18, abbreviated as M1I3P1 and M1I3P2, were able to attain the maximum compression pressure at ankle up to $21 \mathrm{mmHg}$ and $23 \mathrm{mmHg}$ and the minimum pressure up to $17 \mathrm{mmHg}$ at calf in each sample. This difference was managed to achieve the optimum graduation between $70 \%$ and $80 \%$. The achieved graduation percentage (G \%) of both samples was $80 \%$ and $73 \%$, suitable to steam line the flow of blood from ankle to calf and then to rest of the body.

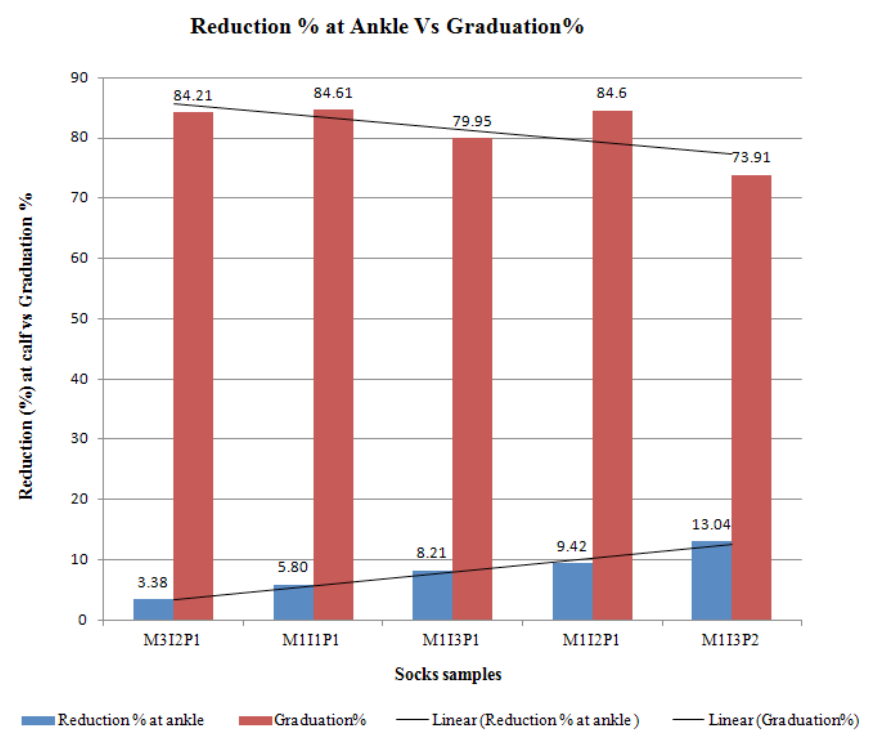

Figure 8. Reduction \% at ankle vs. graduation \% Reduction (\%) at Calf Vs Graduation (\%)

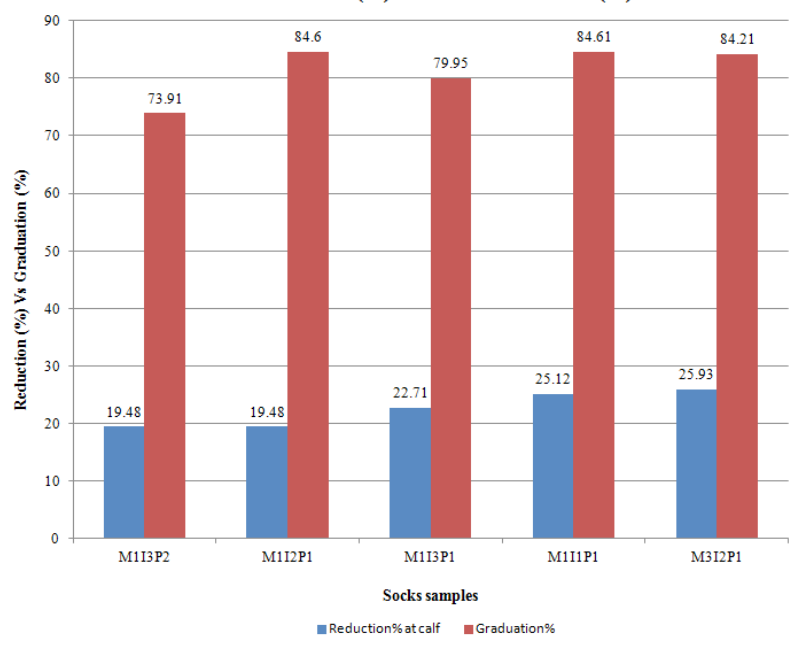

Figure 9. Reduction percentage at calf vs. graduation $\%$

\section{ACKNOWLEDGEMENTS}

This work was supported by the Ministry of Industry and Trade of the Czech Republic, Programme Trio - project "Senior Tex - Smart Modular Clothing and Textile Products with Integrated Electronic Microsystems for Improving the Health Care of the Aging Population and Handicap People", reg. no. FV10111 as well as under the project of Student Grant Scheme SGS-18. Project reference number is 21246 .

\section{References}

[1] Flaud, P., Bassez, P. and Counord, J.L. (2010). Comparative in vitro study of three inter-face pressure sensors used to evaluate medical compression hosiery. Dermatologic Surgery, 12, 1930-1940.

[2] Harpa, R., Piroi, C. and Radu. C.D. (2010). A new approach for testing medical stockings. Textile Research Journal, 80 , 683-695. 
[3] Smith, M.W.L. and Dalbey, J.C. (2011). Gradient compression hosiery knitted using corespun yarns. U.S. patent 7895863-B2.

[4] Wang, Y., Zhang, P. and Zhang, Y. (2014). Experimental investigation the dynamic pressure attenuation of elastic fabric for compression garment. Textile Research Journal, 84, 572-582.

[5] Macintyre, L. and Baird, M. (2005). Pressure garments for use in the treatment of hyper-trophic scars - an evaluation of current construction techniques in NHS hospitals. Burns, 31, 11-14.

[6] Partsch, H. (2005). The use of pressure change on standing as a surrogate measure of the stiffness of a compression bandage. European Journal of Vascular and Endovascular Surgery, 30, 415-421.

[7] Liu, R., Kwok, Y.L., Li, Y., Lao, T.T., Zhang, X., Dia, X.Q., et al. (2005). Objective evaluation of skin pressure distribution of graduated elastic compression stockings. Dermatologic Surgery, 31, 615-624.

[8] Partsch, H., Partsch, B., Braun, W. (2006). Interface pressure and stiffness of ready made compression stockings: comparison of in vivo and in vitro measurements. Journal of Vascular Surgery, 44, 809-814.

[9] Bera, M., Chattopadhay, R., Gupta, D. (2014). The effect of fibre blend on comfort characteristics of elastic knitted fabrics used for pressure garments. Journal of The Institution of Engineers, 95, 41-47.

[10] Oğlakcioğlu, N., Sari, B., Bedez, T., Marmarali, A., et al. (2016). A novel medical bandage with enhanced clothing comfort. Materials Science and Engineering, 141,120-21.

[11] Liu, R., Kwok, Y.L., Li, Y., Lao, T. (2010). Fabric mechanicalsurface properties of compression hosiery and their effects on skin pressure magnitudes when worn. Fibres and Textiles in Eastern Europe, 79, 91-97.

[12] Chimeh, M.Y., Tehran, M.A., Latifi, M., Mojtahedi, M.R.M., et al. (2005). Characterizing bulkiness and hairiness of air-jet textured yarn using imaging techniques. Journal of Textile Institute, 96, 251-255.
[13] Capurro,S., (2004). "Sheathed elastic surgical thread", U.S. patent 10/543333.

[14] Chattopadhyay, R., Gupta, D., Bera, M. (2012). Effect of input tension of inlay yarn on the characteristics of knitted circular stretch fabrics and pressure generation. Journal of Textile Institute, 103, 636-642.

[15] RAL-GZ 387/2 (2008) Medical Compression Armsleeves

[16] Ng S. F., Hui C. L. (2001). Effect of aspect ratio on pressure change of a tubular elastic fabric. Textile Research Journal, 71, 381-383.

[17] DeVasconcelos, F.B., Casaca, F., DeVasconcelos F.G. (2013). Design of elastic garments for sports in circular knitting. International Journal of Textile Fashion and Technology, 3, 39-48.

[18] Tsujisaka, T., Azuma, Y., Matsumoto, Y.I., Morooka, H., et al. (2004). Comfort pressure of the top part of men's socks. Textile Research Journal, 74, 598-602.

[19] Troynikov O., Ashayeri E., Burton M., Subic A., Alam F., Marteau S., et al. (2010). Factors influencing the effectiveness of compression garments used in sports. APCST Procedia Engineering, 2, 2823-2829.

[20] Gaied I., Drapier S., Lun B. (2006). Experimental assessment and analytical $2 d$ predictions of the stocking pressures induced on a model leg by medical compressive stockings. Journal of Biomechanics, 39, 3017-25.

[21] Troynikova O., Wardiningsiha W., Koptugb A., Watsona C., Oggiano L., et al. (2013). Influence of material properties and garment composition on pressure generated by sport compression garments. APCST Procedia Engineering, 157-162.

[22] Tezel S., Kavusturan Y. (2008). Experimental investigation of effects of spandex brand and tightness factor on dimensional and physical properties of cotton/spandex single jersey fabrics. Textile Research Journal, 71, 966976. 